\title{
Enabling Employee Entrepreneurship in Large Technology Firms
} Walter Miron and David Hudson

\author{
"The more people you have to ask for permission,") \\ the more dangerous a project gets.
}

Alain de Botton

Writer, documentary film maker, and entrepreneur

\begin{abstract}
Managers of development projects in large technology firms face a dilemma. They operate under pressure to achieve predictable quality, cost, and schedule objectives but are also expected to encourage their employees to act entrepreneurially. Given the uncertain nature of the entrepreneurial process, these managers often cling to existing practices and values and consequently inhibit their employees' ability to act entrepreneurially.
\end{abstract}

In this article, we examine the product development and entrepreneurship literature streams to identify the barriers that managers of development projects of large technology firms face in allowing employees to act entrepreneurially. We organize these barriers using the five components of entrepreneurial orientation: risk taking, proactiveness, innovativeness, competitive aggressiveness, and autonomy. Then, building on the literature and our combined 40 years of experience managing development projects in large technology firms, we provide recommendations to managers on how to overcome these barriers.

\begin{abstract}
A better understanding of how to enable employees to act entrepreneurially will increase the entrepreneurial orientation of development projects in large technology firms. The relationship between entrepreneurial orientation and development project performance is expected to be curvilinear. Therefore, an increase in entrepreneurial orientation is expected to improve the performance of development projects up to a point after which it is expected to decrease it.
\end{abstract}

This article will be particularly relevant to researchers interested in the relationship between entrepreneurial orientation and project performance as well as managers in technology firms who want to achieve their operational milestones while maximizing the entrepreneurial value creation of their employees.

\section{Introduction}

Managers of large technology firms are routinely expected to improve the performance of their development projects. This expectation arises because of the need for firm competitiveness and because externalization of technology development through outsourcing and acquisition is an alternative to internal product projects (Granstrand and Sjölander, 1990; tinyurl.com/mhtrv77). Improvements can take the form of increased revenue from project outcomes, reduced project development costs, or reduced time to market.
Entrepreneurial orientation describes the extent to which a firm is able to capture new value in the marketplace beyond its existing products, services, and customers (Covin and Slevin, 1989: tinyurl.com/6drqgjk; Lumpkin and Dess, 1996: tinyurl.com/qxsxa57; Miller, 1983: tinyurl.com/cus88fa; Schillo, 2011: timreview.ca/article/497). Can increasing the entrepreneurial orientation of the project development organization within a firm provide the required improvement in development project performance? How can managers in large technology firms apply the concept of entrepreneurial orientation to improve their project development performance? And 


\section{Enabling Employee Entrepreneurship in Large Technology Firms}

\section{Walter Miron and David Hudson}

how can managers overcome the barriers preventing development project team members from acting entrepreneurially in large technology firms?

In this article, we review the literature on entrepreneurial orientation and employee entrepreneurship. We propose how the components of entrepreneurial orientation can be understood at the development project level and then examine the obstacles to employee entrepreneurship within development projects using the component framework from entrepreneurial orientation. Finally, we provide a tool that managers of development projects can use to help their project members overcome the obstacles to employees acting entrepreneurially in large technology firms. Our intent is to better support employees who think and act entrepreneurially for the purpose of increasing the entrepreneurial orientation of project development organizations in the expectation that this increase will lead to better development project performance.

\section{Entrepreneurial Orientation and Entrepreneurial Employees}

The literature suggests that increasing the entrepreneurial orientation of a technology firm leads to increased firm performance (Rauch et al., 2009; tinyurl.com/ $3 \mathrm{kjbwfr}$. That is, there is a relationship between a firm's ability to create and capture new value and the firm's overall profitability. The literature also indicates that the relationship between entrepreneurial orientation and firm performance may be curvilinear, and beyond some threshold, an increase in entrepreneurial orientation no longer improves firm performance and may have a negative impact (Schillo, 2011; timreview.ca/ article/497). Consequently, there is a range where firms with low entrepreneurial orientation can benefit from some degree of improvement.

The components of entrepreneurial orientation include:

1. Risk taking: the willingness of the firm to commit of resources to projects with uncertain outcomes

2. Proactiveness: the degree to which the firm leads in its markets rather than follows

3. Innovativeness: the importance of technology and product leadership to the company

4. Competitive aggressiveness: the extent to which a company pursues competitors' markets
5. Autonomy: the extent to which the company allows and supports independent entrepreneurial action

Entrepreneurial orientation has been studied through various techniques at the firm level using these attributes, which were developed from the idea that the "configuration" of the firm affected its ability to be entrepreneurial (Miller, 2011; tinyurl.com/6jjzdkx). In larger firms, configuration could include explicit decisions made concerning strategies, organizational structures, and operational processes as well as implicit attributes such as attitudes of executives. Of course, companies do not innovate; it is the employees who make a company innovative (Blank, 2013; tinyurl.com/adzqhdq). Therefore, it is the entrepreneurial actions of employees including how they do their jobs and how they contribute to project activities that ultimately contribute to the firm's entrepreneurial orientation.

Entrepreneurship research addresses where firms come from (Foss et al., 2007; tinyurl.com/d77uotf) and often focuses on the role of founders but does allow that employees of established firms can be entrepreneurial (Shane, 2012: tinyurl.com/aznwf4n; Thornton, 1999: tinyurl .com $/ \mathrm{m} 732 \mathrm{z} 8 \mathrm{~g})$. One definition of employee entrepreneurship refers to the actions of employees participating in formal corporate venturing (Ireland et al., 2009; tinyurl .com/ltkqfo5) or intrapreneurship programs (Aldrich, 2005; tinyurl.com/7waf4y7). This definition includes a wide range of possible entrepreneurship-related activities such as training, business diversification, internal process and technology innovation, creation of new divisions, recreation of existing divisions, and reallocation of resources - but emphasizes that the initiatives are led by management (Thornton, 1999; tinyurl.com/ m732z8g).

The literature also describes employee entrepreneurship outside of specific programs and management-directed activities. Foss, Foss, and Klein (2007; tinyurl.com/d77uotf) refer to entrepreneurship by employees within established firms as "proxy entrepreneurship". Similarly, Courpasson, Dany, and Marti (2011; tinyurl.com/dx9z9y4) describe "occupational entrepreneuring" where employees are entrepreneurial in the course of doing their jobs. Baker and Nelson (2005; tinyurl.com/ c6svx2e) describe "entrepreneurial bricolage" as improvisational acts by employees. Finally, Rindova, Barry, and Ketchen Jr. (2009; tinyurl.com/l2htbbh) describe entrepreneurial activity within established firms where there is no direct financial benefit to the entrepreneur from "efforts to bring about new economic, social, institu- 


\section{Enabling Employee Entrepreneurship in Large Technology Firms}

\section{Walter Miron and David Hudson}

tional, and cultural environments... with broad change potential". These authors suggest that there are aspects of an employee's environment that may encourage such proxy, occupational, bricolage-like entrepreneurial efforts to bring change within firms.

Consequently, a second definition of employee entrepreneurship is the value-creating actions that employees may personally initiate related to their immediate job responsibility or environment using available assets including assets that the employee obtains herself or himself (Baker and Nelson, 2005: tinyurl.com/c6svx2e; Courpasson et al., 2011: tinyurl.com/dx9z9y4). This type of employee entrepreneurship emphasizes informal and broadly based entrepreneurship by employees within firms rather than founders of new firms or formally sanctioned programs (Baker and Nelson, 2005: tinyurl .com/c6svx2e; Foss et al., 2007: tinyurl.com/d77uotf). This type of employee entrepreneurship is motivated, at least in part, by emancipation or taking control of one's environment rather than personal profit, although it may bring profit to the firm. That is, employees can become entrepreneurial as a reaction to constraints in their environment and the need to remove those constraints. In this definition, employee entrepreneurship is not a program but is voluntarily, day-to-day value creation that employees motivated by the opportunity to increase their control over their own immediate work environment may choose to pursue, or not.

Acts of emancipation by employees who are acting entrepreneurially include seeking autonomy, making declarations to share their activities, and authoring relationships with co-workers and others to increase support for their actions (Rindova et al., 2009; tinyurl.com/ 12htbbh). Such entrepreneurial employees are motivated to create value for themselves in terms of greater control over their environment but can also add value to their firms' products, services, or operations through the same actions.

We propose that entrepreneurial orientation may be applied to development projects within firms, rather than at the firm level, because a firm's projects contribute to its success in the market. The employees, in turn, contribute to the entrepreneurial orientation of a project activity. Using the second definition of employee entrepreneurship, the components of entrepreneurial orientation at the project level must be understood somewhat differently to allow for voluntary entrepreneurial acts by individual employees:
1. Risk taking: employees take risk without reference to managers. Employees might hide their risk taking if the employee perceives that others might not see their actions as legitimate. Employees may not perceive that their actions are risky (Adner and Levinthal, 2008; tinyurl.com/777el7d).

2. Proactiveness: employees initiate the actions that create value for themselves or the firm and, again, may do so without reference to their firm or managers or competition (Courpasson et al., 2011; tinyurl.com/ dx9z9y4).

3. Innovativeness: employees place importance on technology leadership in what they do in their own jobs and improve their firm's business operations or products and services through their personal entrepreneurial efforts at work (Bernoff and Scadler, 2010: tinyurl.com/244l9qz; Hudson, 2012: timreview.ca/article/633).

4. Competitive aggressiveness: employee entrepreneurship may address any constraint in their environment and not just competitors (Rindova et al., 2009; tinyurl.com/l2htbbh). Such effort would not necessarily involve aggressive posturing by employees but could involve efforts to communicate the potential for change and to actively marshal resources to support for innovation.

5. Autonomy: autonomy seeking by reducing uncertainty in their personal environment is one goal of employee entrepreneurship. Autonomy seeking may also be accompanied by making declarations and "authoring" relationships within the firm - that is, arguing for change and marshaling of others to support the change by the employee (Rindova et al., 2009; tinyurl.com/l2htbbh).

We therefore propose that the understanding of entrepreneurial orientation can be extended to development projects within firms by recasting the definition of its components to consider voluntary employee entrepreneurial actions and the potential for employees to act in this manner.

\section{Obstacles to Employees Acting Entrepreneurially}

Given this understanding of entrepreneurial orientation at the development project level and considering voluntary employee entrepreneurship, we now discuss 


\section{Enabling Employee Entrepreneurship in Large Technology Firms} Walter Miron and David Hudson

some of the obstacles that employees may face. The product development and corporate entrepreneurship literature streams were reviewed for the purpose of identifying the obstacles to employees acting entrepreneurially in large technology firms.

Table 1 provides the results of the literature review. The obstacles identified were organized into five categories, each representing a component of entrepreneurial orientation (Schillo, 2011; timreview.ca/article/497). The table identifies the literature used as reference material and how that material applies at the development project level, rather than the firm level, based on the authors' direct experience with development projects.

Obstacles to employees acting entrepreneurially can be identified in the literature for all the components of entrepreneurial orientation (Covin and Slevin, 1989: tinyurl .com/6drqgjk; Lumpkin and Dess, 1996: tinyurl.com/qxsxa57; Miller, 1983: tinyurl.com/cus88fa; Schillo, 2011: timreview.ca/ article/497). Organizational structures and processes can constrain what managers can do within their projects or what employees have time to initiate by constraining capacity to undertake activities, allocating capacity in a top-down manner, and emphasizing incremental rather than disruptive innovation (Burgers et al., 2009: tinyurl.com/pbsaal3; Hornsby et al., 2009: tinyurl.com/lzhonhk; Goldenberg et al., 2001: tinyurl.com/k6ruh62). Reward systems may provide incentives for only incremental improvements or reactive firefighting by employees at the expense of proactive and self-started actions by project employees that might entail unsanctioned exploration and experimentation (Hornsby et al., 2009; tinyurl.com/ lzhonhk). Project-level innovativeness can also be discouraged by a bias towards existing products, architectures, or technologies or even a formal requirement to refer innovation decisions to specific individuals or groups for approval (Burgers et al., 2009; tinyurl.com/ pbsaal3). Innovativeness can also be impeded by a culture that emphasizes maintaining existing products or businesses and treats disruptive projects as fallbacks or insurance in the event that the existing businesses underperform (Burgelman, 1984; tinyurl.com/qb4pxmk). Competitive aggressiveness within projects can be impeded by either complacency, a sense that innovation is someone else's job, or the innovator's dilemma with the result that project members do not feel that they can address constraints, share disruptive innovations, or create relationships to support their innovations (Christensen, 1997: tinyurl.com/o5hap7k; Goldenberg et al., 2001: tinyurl.com/k6ruh62; Rindova et al., 2009: tinyurl.com/ l2htbbh). Project management approaches that emphas- ize the elimination of risky activities through stage-gate models can also limit experimentation and preclude discovery of new value simply because it was not in the project plan (Goldenberg et al., 2001: tinyurl.com/k6ruh62; MacCormack et al., 2001: tinyurl.com/am6axfs). The obstacles to autonomy include management strategies that focus employees on top-down objectives and heavy-handed control to the exclusion of all other activities and discouraging initiative (Burgers et al., 2009: tinyurl.com/pbsaal3; Burgelman, 1984: tinyurl.com/qb4pxmk; Hornsby et al., 2009: tinyurl.com/lzhonhk; Narayanan et al., 2009: tinyurl.com/kvjxw5y).

This discussion of the obstacles identified in Table 1 leads us to consider how managers can help employees overcome the obstacles and act entrepreneurially.

\section{Overcoming Obstacles to Employees Acting Entrepreneurially}

Table 2 suggests how managers of large technology companies can help employees who are part of their development organizations act entrepreneurially. In essence, we are proposing that managers recognize and then address the obstacles to entrepreneurial orientation faced by employees on development projects.

\section{Tool to Increase the Entrepreneurial Orientation of Development Projects}

Managers may not be able to address all obstacles facing their employees, but they should focus on removing selected impediments to an improved entrepreneurial orientation for their projects. They may wish to address a small number of the most significant obstacles initially. This approach is consistent with the understanding from change management literature that reducing a few key counter-forces can be more effective than attempting to increase the pressure for the change or attempting to reduce all counter-forces at once (e.g., Coch et al., 2009; tinyurl.com/qhbx5tk).

We suggest that managers should determine which component of entrepreneurial orientation faces the largest obstacles and begin there.

\section{Risk taking}

Managers can make choices that create a risk-taking culture or microclimate within their projects by taking advantage of organization development techniques (e.g., Beer and Walton, 1987; tinyurl.com/pplm2mn). Entrepreneurially oriented structures within projects can be 


\section{Enabling Employee Entrepreneurship in Large Technology Firms}

Walter Miron and David Hudson

Table 1. Obstacles to employees acting entrepreneurially in development projects of large technology firms

\begin{tabular}{lll}
\hline Component & Obstacles & Supporting Literature \\
\hline Risk Taking & $\begin{array}{l}\text { A corporate culture that discourages } \\
\text { experimentation at the project level }\end{array}$ & $\begin{array}{l}\text { Burgers et al. (2009; tinyurl.com/pbsaal3) discuss the impact that } \\
\text { corporate structures limiting autonomy at the project level have } \\
\text { on innovation and experimentation. Limiting autonomy between } \\
\text { development teams leads to employees that are risk averse and } \\
\text { who demonstrate low entrepreneurial orientation (Hornsby et al., } \\
\text { 2009: tinyurl.com/lzhonh; Goldenberg et al., 2001: } \\
\end{array}$ \\
& tinyurl.com/k6ruh62). \\
\hline
\end{tabular}

Staffing of new projects with employees who are busy doing other things, in order to minimize risk to near term deliverables
Shared objectives and rewards of the top management team inhibit the allocation of scarce human resources to projects, resulting in project leaders utilizing resources that are overtaxed and motivated exclusively by near-term goals, impacting innovation (Burgers et al., 2009; tinyurl.com/pbsaal3).
Allocating available resources to enhance what exists or add more features to what exists
Encumbered by investments made in current products, firms are motivated to avoid disruption of their own markets and focus efforts on project activities that provide improvements to existing portfolios (Burgelman, 1984; tinyurl.com/qb4pxmk).

\section{Proactiveness Rewarding those who improve efficiency and delivery in current product lines and contributions to performance to corporate scorecards, not those who wish to launch and grow new product lines}

Encouraging employees to focus on existing projects rather than experimentation or starting initiatives on their own

$\begin{array}{ll}\text { Innovativeness } & \begin{array}{l}\text { Discouraging solutions "not invented } \\ \text { here" }\end{array}\end{array}$

$\begin{array}{ll}\text { Innovativeness } & \begin{array}{l}\text { Discouraging solutions "not invented } \\ \text { here" }\end{array}\end{array}$ here

Discouraging new ideas and
experimentation to define ne

Discouraging new ideas and
experimentation to define new solutions solutions
Entrepreneurial behaviours are impeded by the development manager's inability to interpret the wider strategic context of the firm, preoccupation with improving efficiency and maintaining stability, and limited discretion in hiring staff and work assignment (Hornsby et al., 2009; tinyurl.com/lzhonhk).

Wider company processes limit the development manager's ability to proactively engage in entrepreneurial practices (Burgelman, 1984; tinyurl.com/qb4pxmk).
Poor processes and systems to incorporate knowledge created outside of the firm discourage the use of partners and external solutions by development managers constraining projects to depend on internal solutions and authorities (Nayayanan et al., 2008; tinyurl.com/kvjxw5y).

Burgers et al. (2009; tinyurl.com/pbsaal3) explain that social integration of top-level managers with shared objectives and rewards can result in a lack of intrinsic motivation to innovate. Rather than encouraging innovation, this leads to a project-level bias toward protecting investments in existing product lines and processes.

Treating innovation as insurance rather than a primary goal
Burgelman (1984; tinyurl.com/qb4pxmk) states that processes used in the definition, project-impetus, and strategic context-setting phases of new projects can isolate the senior management team from the project leaders. One result can be a perception that new product or venture development is pursued as insurance against decline in existing portfolios rather than being pursed with the goal of replacing the existing business. 


\section{Enabling Employee Entrepreneurship in Large Technology Firms}

Walter Miron and David Hudson

Table 1 (continued). Obstacles to employees acting entrepreneurially in development projects of large technology firms

\begin{tabular}{lll}
\hline Component & Obstacles & Supporting Literature \\
\hline $\begin{array}{lll}\text { Competitive } \\
\text { Aggressiveness }\end{array}$ & $\begin{array}{l}\text { Lack of an adequate vision of why the } \\
\text { company will win in the marketplace }\end{array}$ & $\begin{array}{l}\text { Using ill-defined ideation processes leads project leaders to } \\
\text { develop features aimed solely at their high-end customers, } \\
\text { leaving the low end of their market open to attack by competitors } \\
\text { with inferior products (Christensen, 1997: tinyurl.com/o5hap7k; } \\
\text { Goldenberg et al., 2001: tinyurl.com } / \mathrm{k} 6 \mathrm{ruh} 62) .\end{array}$ \\
\hline
\end{tabular}

Reviewing project progress without incorporating feedback from customers or other project stakeholders
Stage-gate or waterfall development methodologies only engage customers late in the project cycle and lack early success determinants, leading to costly failures (Goldenberg et al., 2001: tinyurl.com/k6ruh62; MacCormack et al., 2001: tinyurl.com/am6axfs). These methodologies also encourage detailed upfront planning to minimize risk, which discourages experimentation and unsanctioned activities.

\section{Autonomy}

Discouraging the need for change or preventing marshaling relationships with others to drive change
Development managers are constrained to focus on near-term priorities through their linkages to the existing and mainstream businesses (Burgers et al., 2009: tinyurl.com/pbsaal3; Burgelman, 1984: tinyurl.com/qb4pxmk; Hornsby et al., 2009: tinyurl.com/lzhonhk; Narayanan et al., 2009: tinyurl.com/kvjxw5y). Employees are prevented from orchestrating relationships with others to accomplish their jobs and are required to follow certain channels.

Investing little or no money to improve development processes
The linkage between development processes and innovation development is underestimated or overlooked. Project leaders are constrained by existing processes and methodologies, rather than embracing processes appropriate for innovation (Burgers et al., 2009: tinyurl.com/pbsaal3; Nayayanan et al., 2008: tinyurl.com/kvjxw5y). 


\section{Enabling Employee Entrepreneurship in Large Technology Firms}

Walter Miron and David Hudson

Table 2. Suggestions on how development managers in large technology companies can help employees in development projects act entrepreneurially

\begin{tabular}{lll}
\hline Component & Obstacles & Proposed Solutions \\
\hline Risk Taking & $\begin{array}{l}\text { A corporate culture that discourages } \\
\text { experimentation at the project level }\end{array}$ & $\begin{array}{l}\text { Select development managers based on their ability to interpret } \\
\text { the strategic intent of their projects to put entrepreneurial } \\
\text { activities into context. These managers and their project leaders } \\
\text { can be permitted discretion in project definition, staffing } \\
\text { selection, and rewards structures to encourage innovation } \\
\text { (Burgelman, 1984: tinyurl.com/qb4pxmk; Narayanan et al., 2009: } \\
\text { tinyurl.com/kvixw5; Burgers et al., 2009: tinyurl.com/pbsaal3; } \\
\text { Hornsby et al., 2009; tinyurl.com/lzhonh). }\end{array}$ \\
& & \\
& &
\end{tabular}

Staffing of new projects with employees who are busy doing other things, in order to minimize risk to near term deliverables
Seek team members and partners with high generational experience, thereby enhancing the team's ability to incorporate new information in ways that benefit their project. Experience is measured by the number of project iterations that a team member has experienced (MacCormack et al., 2001: tinyurl.com/am6axfs; Narayanan et al., 2009: tinyurl.com/kvjxw5y).
Allocating available resources to enhance what exists or add more features to what exists
Constrain resources to limit project scope, provide focus on delivery, and allow for experimentation and learning (Fisher, 2012; tinyurl.com/c8yb7rd). Team members can be encouraged to leverage external partners and external capabilities to support the staffing and resource goals of the project (Narayanan et al., 2009; tinyurl.com/kvjxw5y).

Implement reward structures that link problem finding, problem solving, and knowledge development to the success of the project (Hornsby et al., 2009: tinyurl.com/lzhonhk; Burgelman, 1984; tinyurl.com/qb4pxmk).

\section{Proactiveness Rewarding those who improve efficiency and delivery in current product lines and contributions to performance to corporate scorecards, not those who wish to launch and grow new product lines}

Encouraging employees to focus on existing projects rather than experimentation or employees starting initiatives on their own
Create an organizational structure within the project that allows entrepreneurial activity to be conducted autonomously from the mainstream business to insulate against influence of near-term goals (Burgelman, 1984: tinyurl.com/qb4pxmk; Narayanan et al., 2009: tinyurl.com/kvjxw5y; Burgers et al., 2009: tinyurl.com/pbsaal3; Hornsby et al., 2009: tinyurl.com/lzhonhk).

Innovativeness Discouraging solutions "not built here"

Employ project controls that ensure alignment of activities to corporate strategic context and vision, and that capture and integrate new knowledge (Burgelman, 1984: tinyurl.com/qb4pxmk; Burgers et al., 2009: tinyurl.com/pbsaal3; Narayanan et al., 2009: tinyurl.com/kvjxw5y).

Investing little or no money to improve development processes

Use a dynamic or agile development model rather than stage-gate or waterfall methods to promote collaboration, experimentation, and early customer engagement (MacCormack et al., 2001; tinyurl.com/am6axfs).

Discouraging new ideas and experimentation to define new solutions
Promote collaboration, experimentation, and rapid deployment techniques (Fisher, 2012; tinyurl.com/c8yb7rd), and they should reward outcomes that reflect the innovative nature of the project (Hornsby et al., 2009; tinyurl.com/lzhonhk). 


\section{Enabling Employee Entrepreneurship in Large Technology Firms}

Walter Miron and David Hudson

Table 2 (continued). Suggestions on how development managers in large technology companies can help employees in development projects act entrepreneurially

\begin{tabular}{lll}
\hline Component & Obstacles & Proposed Solutions \\
\hline $\begin{array}{l}\text { Competitive } \\
\text { Aggressiveness }\end{array}$ & $\begin{array}{l}\text { Reviewing project progress without } \\
\text { incorporating feedback from customers } \\
\text { or other project stakeholders }\end{array}$ & $\begin{array}{l}\text { Use early-idea, project, and market-level determinants, such as } \\
\text { customer feedback on minimum viable products, to screen out } \\
\text { potential poor ideas prior to product introduction (Goldenberg et } \\
\text { al., 2001; tinyurl.com/k6ruh62). }\end{array}$ \\
\hline Autonomy & $\begin{array}{l}\text { Discouraging the need for change or } \\
\text { prevent marshaling relationships with } \\
\text { others to drive change }\end{array}$ & $\begin{array}{l}\text { Conduct development autonomously from the mainstream } \\
\text { business (Burgelman, 1984: tinyurl.com/qb4pxmk; Narayanan et al., } \\
\text { 2009: tinyurl.com/kvjxw5y; Burgers et al., 2009: tinyurl.com/pbsaal3; } \\
\text { Hornsby et al., 2009: tinyurl.com/lizhonhk). }\end{array}$ \\
\cline { 2 - 3 } & $\begin{array}{l}\text { Discouraging employees from starting } \\
\text { initiatives on their own }\end{array}$ & $\begin{array}{l}\text { Support the employees' need to increase their control over } \\
\text { uncertainty by authoring work relationships at the project level } \\
\text { (Rindova et al., 2009; tinyurl.com/l2htbbh). }\end{array}$ \\
\hline
\end{tabular}




\title{
Enabling Employee Entrepreneurship in Large Technology Firms
}

\author{
Walter Miron and David Hudson
}

used to lead such change, for example, by allowing for necessary discretion in project definition, staffing selection, and rewards structures. Discretion and delegation here can encourage employee innovation in activities that addresses uncertain and emerging needs. Similar flexibility can be applied at the project level to task prioritization, tool selection, allocation of resources, and so on.

Project staffing considerations begin with the selection of the key project leaders and other critical team members. These people should be selected according to their ability to interpret the strategic context of the project given the desire to also encourage employee entrepreneurial activities. Managers within projects should therefore be allowed discretion with hiring and work assignment of employees (Hornsby et al., 2009; tinyurl.com/ lzhonhk). Both MacCormack, Verganti, and Iansiti (2001; tinyurl.com/am6axfs) and Narayanan, Yang, and Zahra (2009; tinyurl.com/kvjxw5y) tell us that a project development manager should also seek team members and other partners who have high "generational experience", which enhances the team's ability to incorporate the type of new information that might arise from entrepreneurial effort.

\section{Proactiveness}

Managers can seek permission to link rewards for employees assigned to a development project to problem finding, problem solving, and knowledge development (Hornsby et al., 2009: tinyurl.com/lzhonhk; Burgelman, 1984: tinyurl.com/qb4pxmk). The allocation of differential rewards with the project team can therefore also be used to acknowledge and encourage employees who add value through entrepreneurial effort.

\section{Innovation}

Constraining the resources applied to new product development to the lowest level needed to produce a minimum viable product will focus resources on the task at hand and speed delivery (Fisher, 2012: tinyurl.com/ c8yb7rd; Goldenberg et al., 2001: tinyurl.com/k6ruh62). There is also evidence in the literature that constraints can stimulate entrepreneurial effort by employees (Rindova et al., 2009; tinyurl.com/l2htbbh).

Managers can protect and incubate ideas within their projects until they are ready for outsiders. Applying effective ideation reviews leads to better outcomes. Goldenberg, Lehmann, and Mazursky (2001; tinyurl.com/ k6ruh62) advise us that good ideation processes, which utilize early determinants for success at the idea, pro- ject, and market levels, must be employed to ensure success. Focusing reviews on solving problems for the customer, market readiness, and project scope are examples of early determinants that can be used. This same guidance can be applied at the project level to assess employee ideas and to assess their entrepreneurial potential within the project team rather than referring to external authorities or architects.

\section{Competitive aggressiveness}

Knowledge created and captured through project development must be integrated back into the firm, and therefore, managers can define a control mechanism to ensure knowledge capture (Burgelman, 1984: tinyurl.com/ qb4pxmk; Burgers et al., 2009: tinyurl.com/pbsaal3; Narayanan et al., 2009: tinyurl.com/kvjxw5y). Managers must create or encourage forums for knowledge sharing among project employees and provide vehicles for knowledge capture.

\section{Autonomy}

Managers can provide time for individual employees to act entrepreneurially and ensure that rewards account for such initiative. Managers can also recognize that employees will select tools, orchestrate work with others, and take other steps to take control and reduce uncertainty with the result that they create greater value within the project (Rindova et al., 2009; tinyurl.com/ l2htbbh).

\section{Conclusion}

In seeking to encourage technology entrepreneurship in large incumbent technology firms, this article provides a framework that managers can use to support employees acting entrepreneurially. The highlights of the tool developed are:

1. The structure of the tool is based on entrepreneurial orientation literature that argues that firms can be more or less configured or predisposed to being entrepreneurial. We have adapted the entrepreneurial orientation literature to address how managers can encourage and capture entrepreneurial effort to improve the performance of their development projects.

2. We presented the obstacles and solutions to the obstacles to employees acting entrepreneurially by considering the activities of employees working on development projects. The entrepreneurship literature argues that employees of established firms can and do act entrepreneurially. 


\section{Enabling Employee Entrepreneurship in Large Technology Firms}

\section{Walter Miron and David Hudson}

3. There are many potential obstacles to employees acting entrepreneurially. We propose that development project managers address a subset of the obstacles to initiate change. Managers can identify the key obstacles to entrepreneurial activity by considering the five components of entrepreneurial orientation as presented in the framework in this article.

We have focused on the relationship between the five entrepreneurial orientation components and project development performance. In addition to examining the project level rather than the firm, we have considered employee entrepreneurship motivated by a desire to increase control and reduce uncertainty. Emancipation - or actions to increase their own control in an uncertain environment - adds a new perspective to entrepreneurial orientation and offers an opportunity for further research into drivers for entrepreneurship within firms. Employees may be motivated to improve their own work environment at the same time as they create value for their firms. The implication is that a development project manager can encourage such employee entrepreneurship to improve their project's performance.

\section{About the Authors}

Walter Miron is a Director of Technology Strategy at TELUS Communications, where he is responsible for the evolution of their TCP/IP and optical networks. He has over 20 years of experience in enterprise and service provider networking conducting technology selection and service development projects. Walter is a member of the research program committee of the SAVI project, the Heavy Reading Global Ethernet Executive Council, the ATOPs SDN/nFV Working Group, and he represents TELUS at the Venus Cybersecurity Corporation and Invest Ottawa. He is frequently a speaker at industry conferences and working groups. Walter is currently a graduate student in the Technology Innovation Management (TIM) program at Carleton University in Ottawa, Canada.

David Hudson is a lecturer in information technology and innovation in the MBA program at Carleton University's Sprott School of Business in Ottawa, Canada. He is a Director of the Venus Cybersecurity Corporation and the Lead To Win entrepreneurship program, and he is the Chair of the Advisory Board for the Province of Ontario Centres of Excellence Information, Communication, and Digital Media Sector. David also consults with F500 firms on innovation management. David's doctoral research at Carleton focused on IT consumerization and how employees create value for themselves and their firms when they "BYOD". Previously, he was the Vice President for advanced research and development at a large technology firm and has had an extensive career in technology development and product line management. David received Bachelor's and Master's degrees in Systems Design Engineering from the University of Waterloo, Canada.

Citation: Miron, W. and D. Hudson. 2014. Enabling Employee Entrepreneurship in Large Technology Firms. Technology Innovation Management Review. February 2014: 23-32.

Keywords: entrepreneurial orientation, employee entrepreneurship, intrapraneurship, corporate venturing, risk taking, proactiveness, innovativeness, competitive aggressiveness, autonomy, value creation, development projects, emancipation 